УДК 316.48

DOI $10.21661 / \mathrm{r}-554934$

\title{
В.Н. Найденко
}

\section{ЭФФЕКТИВНОСТЬ ДЕЯТЕЛЬНОСТИ СУБЪЕКТОВ ПО ПРЕСЕЧЕНИЮ ЭТНОНАЦИОНАЛЬНЫХ КОНФЛИКТОВ В РОССИИ}

Аннотация: проведённый автором статьи опрос (с применением методов анкетирования и глубинного интервью) 20-ти экспертов, являющихся высококвалифицированными спец̧иалистами в области противодействия этноконфликтам, результаты массового социиологического исследования ВЦИОМ о казачестве, а также анализ научных работ и публикаџиий СМИ по теме исследования позволили определить степень эффективности деятельности основных субъектов в сфере пресечения этнорелигиозных конфликтов. Максимально эффективныли (оченка «5») признаны действия ФСБ и Наџионального антитеррористического комитета (НАК). Достаточно высоко эксперты оцеенли эффективность работь Росгвардии и полиции («4»). Среднюю оценку эфффективности деятельности по пресечению этноконфликтов («3») получили казаческие организации. Недостаточно высоко («2») эксперты оценивают эффективность деятельности добровольных народных дружин и других обществвенньх формирований правоохранительной направленности.

Ключевые слова: пресечение этноначиональных конфликтов, ФСБ, Национальный антитеррористический комитет, Росгвардия, полицуия, казаческие организации, добровольные народнье дружиньл.

Результаты проведённых исследований свидетельствуют о наличии в российском обществе этнорелигиозной напряжённости и соответствующих негативных проявлений. В этих условиях возникают этнонациональные и этнорелигиозные конфликты, которые представляют реальную угрозу политической стабильности и общественной безопасности Российской Федерации, ведут к массовым нарушениям прав российских граждан [13; 14]. 
«Стратегия противодействия экстремизму в Российской Федерации до 2025 года» относит межнациональные (межэтнические) противоречия и конфликты в нашей стране к основным угрозам национальной безопасности. Этнонациональные конфликты приводят к сепаратистским проявлениям, «заключающимся в попытках нарушения территориальной целостности Российской Федерации (в том числе отделения части ее территории) или дезинтеграции государства, а также в организации и подготовке таких действий, пособничестве в их совершении, подстрекательстве к их осуществлению» [18].

Этнонациональные (расовые) конфликты, возникающие вследствие развития негативных экстремистских процессов, получили достаточно широкое распространение в мире.

Так, по данным американских источников в период с 2017 г. по 2019 г. в результате преступлений террористической направленности, совершенных гражданами США на территории страны, погибли 57 человек. При этом значительная часть летальных случаев - 47 - связана с преступлениями сторонников идей превосходства белой расы [16].

Согласно статистическим данным, приведенным в мае 2021 г. в совместном докладе ФБР и Министерства национальной безопасности США, 2019 г. оказался «наиболее летальным» за последние четверть века в контексте террористических преступлений - в результате пяти отдельных нападений «внутренних террористов» погибли 32 человека, из них 24 стали жертвами именно «белых расистов». По данным влиятельного аналитического Центра стратегических и международных исследований (Вашингтон), в период с 2015 г. по 2020 г. в США было совершено или подготовлено 405 террористических акций «с преднамеренным применением или угрозой применения насилия»; их организаторами выступали «негосударственные акторы», которые стремились «достичь политических целей и создать масштабный психологический эффект». Число подобных терактов в указанный период оказалось вдвое больше, чем за предшествующее десятилетие, при этом две трети преступных деяний подобного рода совершались 
сторонниками идей превосходства белой расы, незаконными вооруженными группами и другими ультраправыми элементами [16].

В последнее время в Российской Федерации также фиксируется существенный рост экстремистских, в т.ч. и террористических, проявлений.

По данным МВД России, только в январе-августе 2021 г. в нашей стране зарегистрировано 1607 преступлений террористического характера и 769 преступлений экстремистской направленности. При этом количество преступлений экстремистской направленности выросло на 31,5\% по сравнению с аналогичным периодом 2020 г. [5].

Значительное количество террористических и экстремистских преступлений, как показало исследование, является следствием этноконфликтов и совершается по мотивам этнорелигиозной вражды и ненависти.

В феврале 2021 г. органами ФСБ России проведена комплексная антитеррористическая операция в Карачаево-Черкесской Республике, Республике Крым, Краснодарском крае и Ростовской области. В ходе операции задержаны 19 участников международной исламистской организации «Ат-Такфир валь-Хиджра» («Искупление и исход»), которая признана террористической и запрещена в Российской Федерации. По экспертным оценкам «Ат-Такфир валь-Хиджра» является одной из наиболее радикальных международных исламистских террористических группировок. Ее активисты проповедуют полный разрыв с современным мусульманским обществом, считая его «неверным», и преследуют цель «создания теократического исламского государства - халифата».

Помимо пропаганды экстремистской идеологии (изъято более 40 экземпляров экстремистских материалов) и вербовки новых сторонников, задержанные такфиристы планировали совершение диверсионно-террористических актов на территории Северного Кавказа. Во время обысков по местам пребывания подозреваемых в лесном массиве Карачаево-Черкесии обнаружен тайник с пулеметом РПК, автоматом АКМ, патронами и самодельными взрывными устройствами общей массой более 3 кг в тротиловом эквиваленте, в том числе пояс смертника с поражающими элементами. Десять организаторов и активных 
участников экстремистской организации заключены под стражу, им предъявлены обвинения в организации и участии в деятельности экстремистской организации (ч. 1, ч. 1.1, ч. 2 ст. 282.2 УК РФ) [19].

В сентябре 2021 г. ФСБ России задержала в г. Уфе, Башкирия, пятерых членов неонацистской группировки (возраст от 17 до 20 лет), которые занимались подготовкой терактов «в отношении органов государственной власти и правоохранительных структур». В местах проживания подозреваемых и в тайнике, оборудованном на одной из заброшенных строек в Уфе, обнаружены готовое самодельное взрывное устройство, инструкции и компоненты для изготовления других взрывных устройств, девять единиц холодного оружия, портреты главарей Третьего рейха и украинского нациста Степана Бандеры, а также различную националистическую атрибутику. Для подготовки терактов неонацисты проводили соответствующие тренировки в лесу. Следственный комитет России возбудил в отношении участников группировки уголовные дела по ч. 1 ст. 30, ч. 1 ст. 205 («Приготовление к террористическому акту»), 205.3 («Прохождение обучения в целях осуществления террористической деятельности»), ст. 223.1 («Незаконное изготовление взрывчатых веществ или взрывных устройств») УК РФ. Подозреваемых заключили под стражу [7; 20].

Поэтому важнейшей задачей российских государственных и общественных организаций является противодействие экстремистской деятельности, своевременное пресечение возникающих этнорелигиозных конфликтов и иных негативных проявлений этнического характера, формирование в обществе атмосферы нетерпимости к распространению этнонациональных экстремистских идей.

Эффективная деятельность по пресечению этноконфликтов будет в немалой степени способствовать решению важных задач по укреплению гражданского единства, достижению межнационального (межэтнического) и межконфессионального согласия, сохранению этнокультурного многообразия народов России. Подробнее об этом см.: [2; 8; 12; 15].

Важной научной и практической задачей является оценка эффективности деятельности основных субъектов пресечения этнорелигиозных конфликтов и 
выяснения мнений экспертов об оправданности использования при этом добровольных общественных формирований правоохранительной направленности (казаческих организаций, ДНД и др.).

Для решения этой задачи в январе - апреле 2021 г. был проведён двухэтапный опрос 20 экспертов, включавший анкетирование и глубинное интервью. Вначале эксперты заполнили заранее подготовленную по теме исследования анкету. После этого, в соответствии с разработанным гайдом глубинного интервью, было проведено их интервьюирование. В каждом случае гайд адаптировался в зависимости от хода интервью, а также с учётом потенциала и интересов каждого эксперта.

Опрошенные эксперты являются квалифицированными специалистами в сфере деятельности международных организаций, российских органов государственной и муниципальной власти, правоохранительных органов, в области юриспруденции, науки, образования и культуры. Они имеют опыт работы в Экспертно-аналитическом управлении Секретариата Совета Межпарламентской Ассамблеи СНГ, Антитеррористическом центре СНГ, Евразийском информационно-аналитическом консорциуме, Совете Безопасности Российской Федерации, Федеральной службе безопасности Российской Федерации, аппарате Национального антитеррористического комитета, Министерстве юстиции Российской Федерации, Министерстве науки и высшего образования Российской Федерации, Главном управлении региональной безопасности Московской области, Московском госуниверситете им. М. В. Ломоносова, Московском государственном институте международных отношений (Университет) МИД России, профессиональном сообществе аналитиков «Русская аналитическая школа».

Эксперты имеют практический, аналитический, научный и педагогический опыт в области обеспечения безопасности Российской Федерации в этнонациональной сфере. Некоторые из них имеют опыт проведения научных исследований и преподавательской работы в области противодействия этнонациональным конфликтам. 
В ходе экспертного опроса исследовалась эффективность деятельности различных государственных и общественных структур по пресечению, в т. ч. с использованием силы, этнорелигиозных конфликтов и анализировалась практика использования в этих целях добровольных общественных формирований правоохранительной направленности. Сам перечень основных субъектов деятельности по пресечению этноконфликтов предварительно обсуждался с экспертами, их обоснованные предложения по этому вопросу были учтены при разработке гайда глубинного интервью.

Опрашиваемым экспертам был задан вопрос: «Как Вы оцениваете степень эффективности деятельности основных субъектов Российской Федерации по пресечению этнорелигиозных конфликтов». Эффективность этой деятельности оценивались экспертами по шкале от «1» до «5», где «1»-минимальная эффективность, «5»- максимальная эффективность. Результаты анализа экспертных оценок приведены в таблице 1.

Таблица 1

Оценка эффективности деятельности основных субъектов по пресечению этнорелигиозных конфликтов, 2021 г. (один ответ по каждому субъекту, N=20)

\begin{tabular}{|l|c|}
\hline \multicolumn{1}{|c|}{ Субъекты } & $\begin{array}{c}\text { Оиенка эффоективности } \\
\text { (средние величиньл } \\
\text { по выборке) }\end{array}$ \\
\hline ФСБ & 5 \\
\hline НАК & 5 \\
\hline Росгвардия & 4 \\
\hline Полиция & 4 \\
\hline Казаческие организации & 3 \\
\hline $\begin{array}{l}\text { ДНД и др. общественные формирования правоохрани- } \\
\text { тельной направленности }\end{array}$ & 2 \\
\hline
\end{tabular}

Как видно из данных таблицы 1, максимально позитивную оценку эффективности деятельности по пресечению этноконфликтов (5) получили ФСБ и HAK. 
Оценивая деятельность органов ФСБ, один из экспертов отметил:

«Органьл ФСБ демонстрируют наибольшую эффективность в выявлении, предупреждении и пресечении этнорелигиозной экстремистской деятельности, и прежде всего наиболее опасных её форм- проведения террористических акцุий, создания подпольньхх структур и незаконных вооружённых формирований, развязывания «партизанских» войн, организации вооружённых мятежей, попьток осущуествления неконституцуионного захвата власти. ФСБ России располагает для этого соответствующими силами и средствами и результативно применяет контрразведывательные методы. Во многом благодаря успешной оперативной работе ФСБ подавляющее больиинство опасных этноэкстремистских конфликтов своевременно пресекается и локализуется с подключением возможностей НАК, Росгвардии и полищуии».

НАК обеспечивает координацию антитеррористической деятельности федеральных органов исполнительной власти, органов исполнительной власти субъектов Российской Федерации и органов местного самоуправления. Для организации применения сил и средств федеральных органов исполнительной власти и их территориальных структур в борьбе с терроризмом, а также для управления конкретными контртеррористическими операциями (КТО) в составе НАК функционирует Федеральный оперативный штаб, которым руководит Директор ФСБ России, а для управления КТО в субъектах Российской Федерации - оперативные штабы, возглавляемые руководителями территориальных органов ФСБ.

Достаточно высокую оценку эффективности работы по пресечению этноконфликтов («4») получили Росгвардия и полиция (см. табл. 1).

Только с 2016 г. по 2021 г. при активном участии Росгвардии Объединенной группировкой войск (сил) на территории Северо-Кавказского региона Российской Федерации проведено свыше 4 тыс. специальных операций, в ходе которых ликвидировано 250 боевиков, обнаружено и уничтожено 29 баз подготовки незаконных вооруженных формирований, 193 стоянки боевиков и 517 схронов (тайников). В этот же период времени изъято 4,5 тыс. единиц огнестрельного оружия, около 300 тыс. боеприпасов, более тонны взрывчатых веществ [6]. 
Подразделения Росгвардии эффективно используются как силовая составляющая при пресечении этноконфликтов, а также для обеспечения безопасности проводимых полицией оперативно-разыскных и специальных операций (мероприятий) и следственных действий. В ходе пресечения этноконфликтов росгвардейцы выполняют также задачи по обеспечению безопасности лиц, подлежащих государственной защите, а в случаях необходимости - конвоирования и охраны подозреваемых и обвиняемых в совершении тяжких и особо тяжких преступлений, совершенных организованной группой или преступным сообществом этноэкстремистской направленности [1;9].

Среднюю экспертную оценку эффективности деятельности по пресечению и локализации этноконфликтов («3») получили казаческие организации (табл. 1).

Результаты исследования российского казачества как социокультурной общности, которая исторически сложилась на основе взаимодействия русского народа и других народов России в ходе многовекового служения казаков Российскому государству и обществу [3; 4; 11], свидетельствуют о высоком потенциале казаческих организаций для эффективного решения задач в сфере обеспечения национальной безопасности нашей страны [17].

Так, оценивая роль казачества в предупреждении и пресечении этнонациональных конфликтов, один из экспертов отмечает:

«Казачество играет положительную, стабилизирующую роль в этнонациональной сфере. В России сейчас около 7 миллионов человек причисляют себя к казакам. Общая численность участников войсковых казачьих обществ превышает 700 тысяч человек. Я неоднократно наблюдал работу казачьих патрулей, которые участвуют в охране общественного порядка в некоторых российских городах. Как правило, к ним с уважением относятся простые граждане. Казаческие организаџии сохраняют самобытную казачью культуру и традиции, в патриотическом духе воспитьвают молодое поколение казаков.

Особенно полезны казаческие организации в приграничных территориях, там, где регионы с русскоязычным населением граничат с территориями проживания других этносов. Во время чеченской кампании органы безопасности 
неоднократно получали информациию о том, что северокавказские боевики ненавидят и очень боятся казаческих формирований типа «войсковых казачьих общуеств», «отрядов самообороныл», «защчищенных станицу» и т. n. В этих структурах организованы чаще всего родственники или соседи, которые дорожат своей честью, не предадут, друг перед другом не опозорятся, постараются защุитить товарищуа. Сплоченность казаков и их умение обращуаться с оружием нациионал-экстремистским боевикам очень не нравится и вызывает у них обоснованный страх. Поэтому действуюшие на Северном Кавказе боевики неоднократно предпринимали усилия (в т.ч. в информациинной сфере), направленнье на компрометацуию, развал казачьих организациий и даже запрет их деятельности в Российской Федерацииџ».

Другой эксперт заявил:

«Казаческое движение - это очень здоровая общественная инициатива, которая может быть эффективно использована в обеспечении национальной безопасности, в т. ч. для пресечения и локализации этноконфликтов. Поэтому казачество как сочиально-этническое образование по праву заслуживает государственной поддержки и положительной оценки российского общеетва.

Вместе с тем, органы власти должны держать эту сферу под постояннымм контролем, чтобы не дать в среде казачества прорасти росткам радикального национализма и сепаратизма. Надо помнить о законе США 1959 года «O порабощенных нацчиях», в котором среди наџиональных образований, якобы нуждаюшихся в «освобождении», указана «Казакия», так называемая «страна казаков», примерно совпадающая в границах с очертаниями Южнного Федерального округа. Мы не можем и не должны допустить использования казаческих организаџий для инспирирования сепаратистских или антироссийских движениц̆».

Проведённое ВЦИОМ в 2017 г. исследование «Казачество Северного Кавказа как фактор стабильности региона» позволило определить отношение казачества к методам прекращения конфликтов в мире, в России и в конкретной республике проживания интервьюеров. В качестве метода сбора информации 
использовалось личное формализованное интервью 750 казаков старше 18 лет, проживающих в Северо-Кавказском федеральном округе (Ставропольский край, Республика Дагестан, Чеченская Республика, Республика Северная Осетия, Кабардино-Балкарская Республика, Карачаево-Черкесская Республика, Республика Ингушетия).

Опрашиваемым был задан вопрос: «Какие методы, на Ваш взгляд, наиболее эффективны для прекращения конфликтов?». Результаты анализа оценок интервьюированных казаков приведены в таблице 2.

Таблица 2

Оценка способов разрешения конфликтов (\%) по результатам исследования ВЦИОМ «Казачество Северного Кавказа как фактор стабильности региона», 2017 (один ответ по каждой группе методов, N=750)

\begin{tabular}{|l|c|c|c|}
\hline $\begin{array}{c}\text { Методы разрешения } \\
\text { конфликтов }\end{array}$ & $\begin{array}{c}\text { Мирные, } \\
\text { ненасильственные }\end{array}$ & $\begin{array}{c}\text { Силовые, } \\
\text { насильственные }\end{array}$ & $\begin{array}{c}\text { Другие / } \\
\text { Затрудняюсь } \\
\text { ответить }\end{array}$ \\
\hline Во всём мире в целом & 80 & 17 & 3 \\
\hline В России в целом & 89 & 9 & 2 \\
\hline В вашей республике & 86 & 11 & 3 \\
\hline
\end{tabular}

Приведённые в таблице 2 данные свидетельствуют о настроенности большей части казаков преимущественно на мирное, ненасильственное разрешение конфликтов в нашей стране (89\% в России в целом и 86\% в регионе проживания). Вместе с тем, меньшая часть опрошенных полагает возможным использовать для разрешения конфликтов силовые, насильственные методы (9\% в России в целом и $11 \%$ в регионе проживания) [10].

Недостаточно высокую экспертную оценку эффективности работы по пресечению этноконфликтов («2») получили народные дружины и другие общественные формирования правоохранительной направленности (см. табл. 1). К числу таких общественных формирований относятся ДНД, общественные 
объединения ветеранов «Боевое братство», молодёжные (студенческие) патрули и др.

Наименьшую оценку деятельности по пресечению этнорелигиозных конфликтов («1») не получил ни один из субъектов, выбранных для изучения автором статьи совместно с экспертами перед проведением опроса (табл. 1).

В ходе опроса, проведённого автором настоящей статьи, изучалось мнение экспертов об оправданности использования добровольных общественных формирований правоохранительной направленности (казачества, ДНД и др.) для пресечения, в т.ч. с использованием силы, этнонациональных конфликтов. Результаты проведенного анализа приведены в таблице 3.

Таблица 3

Оценка экспертами оправданности использования добровольных общественных формирований (казачества, ДНД и др.)

для пресечения (в т.ч. с использованием силы) этнонациональных конфликтов, 2021 г. (один ответ по каждому пункту $\mathrm{N}=20$ )

\begin{tabular}{|l|c|}
\hline \multicolumn{1}{|c|}{ Использование добровольных общественных формирований: } & $\begin{array}{c}\text { Количество } \\
\text { ответивших }\end{array}$ \\
\hline $\begin{array}{l}\text { Неоправданно, поскольку только государство имеет право на при- } \\
\text { менение насилия }\end{array}$ & $7(35 \%)$ \\
\hline $\begin{array}{l}\text { Оправданно только в экстренных обстоятельствах, когда государ- } \\
\text { ственные службы не могут (не считают целесообразным) самостоя- } \\
\text { тельно пресечь внезапную угрозу }\end{array}$ & $8(40 \%)$ \\
\hline $\begin{array}{l}\text { Оправданно, поскольку является формой помощи государству со } \\
\text { стороны ответственных граждан }\end{array}$ & $5(25 \%)$ \\
\hline
\end{tabular}

Большая часть экспертов - 65\% (13 чел.) считает оправданным использование добровольных общественных формирований (казачества, ДНД и др.) для пресечения конфликтов в сфере этнонациональных отношений. При этом четверть от общего количества респондентов - 25\% (5 чел.) полагает правильным такое использование практически в любых конфликтных ситуациях, а 40\% опрошенных (8 чел) выступает за использование общественных формирований только в экстренных обстоятельствах, когда государственные службы не могут 
(не считают целесообразным) самостоятельно пресечь внезапную угрозу. См. табл. 3.

Вместе с тем, меньшая часть опрошенных экспертов - 35\% (7 чел.) считает неоправданным использование добровольных общественных формирований, поскольку только государство имеет право на применение насилия (табл. 3).

В свою очередь, меньшая часть - 35\% опрошенных экспертов (7 чел.) считает неоправданным использование добровольных общественных формирований в ходе пресечения этнонациональных конфликтов, поскольку только государство имеет право на применение насилия (табл. 3).

Один из экспертов объяснил ещё одну причину нежелательности использования при этом казаческих структур:

«Среди части казачества до некоторой степени распространень русские националистические идеи. Поэтому считаю неоправданным использование казаческих структур для пресечения этнонациинальных конфликтов, это может обострить конфликтные ситуации с участием нерусских этносов. Нецелесообразно также использовать казаческие организации для пресечения возможных социиально-политических конфликтов, т.к. это вызовет всплеск негативных эмочиий, зачастую необоснованных, по отношению к казачеству. С такими задачами, как показывает практика, успешно справляются подразделения Росгвардии».

Таким образом, анализ эффективности деятельности основных субъектов пресечения этнорелигиозных конфликтов показал, что максимально эффективными (экспертная оценка «5») являются пресекательные действия ФСБ и НАК. Достаточно высоко эксперты оценили эффективность работы Росгвардии и полиции («4»). Среднюю оценку эффективности деятельности по пресечению этноконфликтов («3») получили казаческие организации. Недостаточно высоко («2») эксперты оценивают эффективность деятельности ДНД, общественных объединений ветеранов «Боевое братство», молодёжных (студенческих) патрулей и др. общественных формирований правоохранительной направленности. Наименьшую оценку деятельности по пресечению этнорелигиозных конфликтов 
(«1») не получил ни один из субъектов, выделенных для анализа автором статьи совместно с экспертами перед проведением опроса.

Изучение экспертных оценок об оправданности использования в антиэкстремистской деятельности добровольных общественных формирований правоохранительной направленности (казачества, ДНД и др.) показало, что большая часть - 65\% экспертов (13 чел.) считает оправданным использование их возможностей для пресечения конфликтов в сфере этнонациональных отношений и прежде всего - конфликтов сепаратистской ориентации. При этом четверть $25 \%$ (5 чел.) от общего количества экспертов полагает правильным такое использование практически в любых конфликтных ситуациях, а 40\% (8 чел.) - выступает за использование общественных формирований только в экстренных обстоятельствах, когда государственные службы не могут (не считают целесообразным) самостоятельно пресечь внезапную угрозу. Вместе с тем, меньшая часть 35\% опрошенных экспертов (7 чел.) считает неоправданным использование добровольных общественных формирований, поскольку только государство имеет право на применение насилия.

Проблемы деятельности различных субъектов по предотвращению, пресечению и локализации этноконфликтов оказывают существенное влияние не только на обеспечение национальной безопасности России, но и на укрепление гражданского единства, достижение межнационального и межконфессионального согласия в российском обществе. Поэтому они заслуживают внимания научного сообщества и нуждаются в дальнейших исследованиях.

\section{Сиисок литературы}

1. Абазов А.Б. Анализ и задачи ОВД по предупреждению и пресечению экстремистских действий в современной России // Пробелы в российском законодательстве. - 2018. - №3 [Электронный ресурс]. - Режим доступа: https://cyberleninka.ru/article/n/analiz-i-zadachi-ovd-po-preduprezhdeniyu-ipresecheniyu-ekstremistskih-deystviy-v-sovremennoy-rossii 
2. Бараш Р.Э. Гражданская идентичность россиян: динамика и перспективы // Вестник Российского философского общества. - 2020. - №1-2 (91-92). C. 94-104.

3. Бредихин А.В. Этносоциальная идентичность современного российского казачества // Государственное управление. Электронный вестник. - 2017. - №61 [Электронный $\quad$ ресурс]. https://cyberleninka.ru/article/n/etnosotsialnaya-identichnost-sovremennogorossiyskogo-kazachestva

4. Бугай Н.Ф. Российское казачество и проблема идентичности с вопросом: кто мы? // Вестник ВолГУ. - Серия 4, История. Регионоведение. Международные отношения. - 2019. - №4 [Электронный ресурс]. - Режим доступа: https://cyberleninka.ru/article/n/rossiyskoe-kazachestvo-i-problema-identichnosti-svoprosom-kto-my

5. В МВД заявили о росте числа экстремистских преступлений. - 27.09.2021 [Электронный ресурс]. - Режим доступа: https:/ria.ru/20210927/prestupleniya1751982227.html

6. В Росгвардии сообщили, что с ее участием ликвидировали 250 боевиков за пять лет на Кавказе. - 03.09.2021 [Электронный ресурс]. - Режим доступа: https://tass.ru/proisshestviya/12292627

7. В Уфе задержали готовившую теракт группировку неонацистов. 27.09.2021 [Электронный pecypc]. - Режим доступа: https://tass.ru/proisshestviya/12513169?utm_source=yxnews\&utm_medium=desktop

8. Горшков М.К. Синтез этнонационального и гражданского как основа российской идентичности / М.К. Горшков, И.О. Тюрина // Вестник РУДН. Серия: Социология. - 2018. - №1 [Электронный ресурс]. - Режим доступа: https://cyberleninka.ru/article/n/sintez-etnonatsionalnogo-i-grazhdanskogo-kakosnova-rossiyskoy-identichnosti

9. Грищенко Л.Л. Применение органов внутренних дел и войск национальной гвардии Российской Федерации в мероприятиях по противодействию экстремизму / Л.Л. Грищенко, Б.Н. Кадыров // Академическая мысль. - 2020. - №1 
https://cyberleninka.ru/article/n/primenenie-organov-vnutrennih-del-i-voysknatsionalnoy-gvardii-rossiyskoy-federatsii-v-meropriyatiyah-po-protivodeystviyuekstremizmu

10. Казачество Северного Кавказа как фактор стабильности региона. - М.: ВЦИОМ. - 2017 [Электронный ресурс]. - Режим доступа: https://wciom.ru/fileadmin/file/nauka/ns_doklady/2017/kazachestvo.pdf

11. Коневиченко И.Л. Казачество в правовом пространстве России: история и современность: монография - СПб.: ГУАП, 2016. - 130 с.

12. Межнациональное согласие в общероссийском и региональном измерении. Социокультурный и религиозный контексты: монография / отв. ред. Л.М. Дробижева. - М.: ФНИСЦ РАН, 2018. - 552 с.

13. Найденко В.Н. Напряжённость в этнополитической сфере и оценка возможности этнонациональных конфликтов // Социологическая наука и социальная практика. - 2019. - Т. 7. - №3. - С. 22-39.

14. Найденко В.Н. Экспертная оценка негативных проявлений, обусловливающих этнонациональные конфликты в современной России // Социологическая наука и социальная практика. - 2020. - №3. - С. 149-164.

15. Рыжова С.В. Обобщённое доверие и чувства к России как компоненты общероссийской идентичности // Социологическая наука и социальная практика. - 2021. - Том. 9. - №2. - С. 27-41.

16. Сенин К. Изнутри ужасные: в США зафиксировали рост экстремистских настроений. - 23.05.2021 [Электронный ресурс]. - Режим доступа: https://iz.ru/1165713/kirill-senin/iznutri-uzhasnye-v-ssha-zafiksirovali-rostekstremistskikh-nastroenii

17. Стратегия государственной политики Российской Федерации в отношении российского казачества на 2021 - 2030 годы. Утверждена указом Президента РФ от 9 августа 2020 г. №505 [Электронный ресурс]. - Режим доступа: https://www.garant.ru/products/ipo/prime/doc/74384683/ 
18. Стратегия противодействия экстремизму в Российской Федерации до 2025 года [Электронный ресурс]. - Режим доступа: http://www.consultant.ru/document/cons_doc_LAW_353838/

19. ФСБ задержала экстремистов, планировавших теракты на Юге России. 17.02.2021 [Электронный pecypc]. - Режим доступа: https://www.kommersant.ru/doc/4693753

20. Чиркова Е.В спортивной группе нашли нацистов и террористов. 27.09.2021 [Электронный ресурс]. - Режим доступа: https://www.kommersant.ru/doc/5006999

Найденко Виталий Николаевич - д-р юрид. наук, доцент, главный научный сотрудник, Институт социологии ФГБУН «Федеральный научно-исследовательский социологический центр Российской академии наук», Россия, Москва. 